\title{
Progress in Wind-and-React Bi-2212 Accelerator Magnet Technology
}

\author{
A. Godeke, D. Cheng, D. R. Dietderich, C. R. Hannaford, S. O. Prestemon, G. Sabbi, X. Wang, Y. Hikichi, \\ J. Nishioka, and T. Hasegawa
}

\begin{abstract}
We report on our progress in the development of the technology for the application of $\mathrm{Bi}_{2} \mathrm{Sr}_{2} \mathrm{CaCu}_{2} \mathrm{O}_{8+x}(\mathrm{Bi}-$ 2212) in Wind-and-React accelerator magnets. A series of superconducting subscale coils has been manufactured at LBNL and reacted at the wire manufacturer SWCC. Selected coils are impregnated and tested in self-field, even though the coils exhibited leakage during the partial melt heat treatment. Other coils have been disassembled after reaction and submitted to critical current $\left(I_{c}\right)$ tests on individual cable sections. We report on the results of the current carrying capacity of the coils. Voltage-current $(V I)$ transitions were reproducibly measured up to a quench currents around $1400 \mathrm{~A}$, which is $25 \%$ of the expected performance. The results indicate that the coils are limited by the inner windings. We further compare possibilities to use $\mathrm{Bi}$ 2212 and $\mathrm{Nb}_{3} \mathrm{Sn}$ tilted solenoid, and $\mathrm{YBa}_{2} \mathrm{Cu}_{3} \mathrm{O}_{7-\delta}(\mathrm{YBCO})$ racetrack inserts to increase the magnetic field in $\mathrm{HD2}$, a $36 \mathrm{~mm}$ bore $\mathrm{Nb}_{3} \mathrm{Sn}$ dipole magnet which recently achieved a bore magnetic field of 13.8 T. The application of Bi-2212 and/or YBCO in accelerator type magnets, if successful, will open the road to higher magnetic fields, far surpassing the limitations of $\mathrm{Nb}_{3} \mathrm{Sn}$ magnet technology.
\end{abstract}

Index Terms-accelerator magnets, Bi-2212, high temperature superconductors, YBCO

\section{INTRODUCTION}

$\mathbf{T}$ HE development of technologies to extend acceleratortype superconducting dipole magnets beyond that achievable with $\mathrm{Nb}_{3} \mathrm{Sn}$ is currently under investigation, with the primarily focus on $\mathrm{Bi}-2212$ round wires. The present accelerator dipole prototype record is $16 \mathrm{~T}$ at $4.5 \mathrm{~K}$ [1], and although yet higher fields are attainable with $\mathrm{Nb}_{3} \mathrm{Sn}$ technology, it is evident that $\mathrm{Nb}_{3} \mathrm{Sn}$-based dipole magnets are ultimately limited to 17 to $18 \mathrm{~T}$ [2] and that new materials must be introduced to reach higher fields.

The dominant material candidates are YBCO tapes and Bi2212 round wire, both of which are commercially available and hold promise for reasonable engineering current densities at high field and low temperature. The focus on Bi-2212 material for accelerator applications stems primarily from its availability as round wire, capable of being formed into a high-current conductor using well-proven Rutherford-cable technology. Application of Rutherford cable technology to

Manuscript received August 19, 2008. This work was supported by the Director, Office of Science, High Energy Physics, U.S. Department of Energy under contract No. DE-AC02-05CH11231.

A. Godeke (corresponding author; phone: +1-510-486-4356; e-mail: agodeke@ @lbl.gov), D. Cheng, D. R. Dietderich, C. R. Hanaford, S. O. Prestemon, G. Sabbi, and X. Wang are with Lawrence Berkeley National Laboratory, One Cyclotron Rd., Berkeley, CA 94720, USA

Y. Hikichi, J. Nishioka, and T. Hasegawa are with SWCC Showa Cable Systems, 4-1-1 Minami-Hashimoto, Sagamihara, Kanagawa 229-1133, Japan
Bi-2212 was demonstrated nearly a decade ago [3]. For accelerator applications a wind-and-react (W\&R) approach must be taken, requiring a suite of compatible materials, from conductor insulation to winding and reaction tooling, capable of withstanding the $\sim 900^{\circ} \mathrm{C}$ reaction in pure Oxygen without inhibiting or impacting the formation of the superconducting phases. An HTS program is therefore underway at LBNL to investigate material and fabrication issues associated with W\&R Bi-2212 conductors. The research is focused on multiple fronts:

- Design, fabrication, and test of subscale coils to develop an understanding of coil handling, tooling and testing issues/needs;

- Analysis and experimental campaigns to understand conductor concerns, in particular material compatibility and conductor leakage issues, both for wire and Rutherford cables;

- Investigation of magnet configurations and design issues for insert coils in existing high field dipole magnets, including mechanical loads and magnet protection.

Here we describe coil fabrication (section II) and results of first coil tests (section III). Possible application of Bi-2212 round wire and YBCO tape conductors for insert coils are reviewed in section IV.

\section{Coil manufacture}

A series of six subscale coils has been fabricated and heat treated, and a subset of the coils has been tested at $4.2 \mathrm{~K}$. To fabricate a coil, bare $0.8 \mathrm{~mm}$ diameter wire from the manufacturer is used to create a 17 -strand Rutherford cable using the LBNL cabling facility. The cable is then insulated with a ceramic fiber sleeve prior to coil winding on an INCONEL ${ }^{\circledR}$ Alloy 600 island. Voltage taps are installed during coil fabrication. The wound coil is placed in INCONEL ${ }^{\circledR}$ Alloy 600 support tooling with confinement controlled by shims. The coil is reacted at the manufacturer at $\sim 880^{\circ} \mathrm{C}$ in pure Oxygen following a precise heat treatment schedule.

Table I describes the coils fabricated and heat-treated in collaboration with Showa Cable Systems (SWCC). Coil HTSSC01 was a dummy coil with numerous calibrated thermocouples used to demonstrate that the coil mass could reliably undergo the thermal schedule with sufficiently small temperature gradients. Experience with coils HTS-SC03 and HTSSC05 suggested coil confinement may contribute to leakage; whereas the confined coils showed some leakage, unconfined witness samples did not. Coils HTS-SC07, HTS-SC09, and 
TABLE I

COILS FABRICATED USING SWCC BI-2212 ROUND WIRE.

\begin{tabular}{lcccc}
\hline \hline Coil ID & Strand & Insulation & Sizing & Confinement \\
\hline HTS-SC01 & Ag dummy & ${\mathrm{Pure} \mathrm{SiO}_{2}}$ & present & full \\
HTS-SC03 & Untwisted & $\mathrm{Al}_{2} \mathrm{O}_{3} \mathrm{SiO}_{2}$ & present & full \\
HTS-SC05 & Twisted & $\mathrm{Al}_{2} \mathrm{O}_{3} \mathrm{SiO}_{2}$ & $600^{\circ} \mathrm{C} / 1 \mathrm{hr}$ & full \\
HTS-SC07 & Twisted & $\mathrm{Al}_{2} \mathrm{O}_{3} \mathrm{SiO}_{2}$ & $825^{\circ} \mathrm{C} / 4 \mathrm{hr}$ & Low (X\&Y) \\
HTS-SC09 & Twisted & $\mathrm{Al}_{2} \mathrm{O}_{3} \mathrm{SiO}_{2}$ & $825^{\circ} \mathrm{C} / 4 \mathrm{hr}$ & Low (X) \\
HTS-SC11 & Twisted & $\mathrm{Al}_{2} \mathrm{O}_{3} \mathrm{SiO}_{2}$ & $825^{\circ} \mathrm{C} / 4 \mathrm{hr}$ & Low (Y) \\
\hline \hline
\end{tabular}

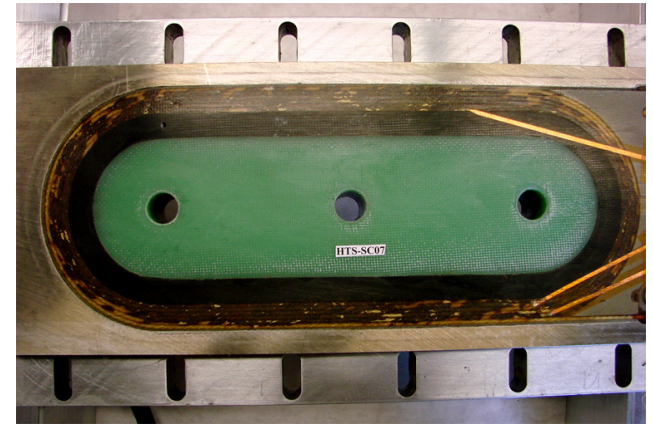

Fig. 1. Reacted, instrumented and impregnated coil HTS-SC07.

HTS-SC11 were therefore designed with varying degrees of confinement: "low (X)" refers to no restriction from side rails; "low (Y)" refers to removal of top-plate during reaction.

\section{BI-2212 COIL MEASUREMENTS}

\section{A. Measurement procedures}

Coils HTS-SC05, HTS-SC07, and HTS-SC09 and their witness cables samples have been analyzed for critical current performance. The witness samples were cooled down in an unconstrained state, and tested for $I_{\mathrm{c}}$ performance at $64 \mathrm{~K}$. Coil HTS-SC09 was deconstructed at room temperature (RT) at SWCC. Partial inner and outer turns from layer 1 and 2, consisting of two straight sections and one curve, were also cooled down in an unconstrained state and tested for $I_{\mathrm{c}}$ at $64 \mathrm{~K}$. The INCONEL ${ }^{\circledR}$ Alloy 600 reaction package of coils HTS-SC05 and HTS-SC07 was removed and the outer coil confinement ('horseshoe' [4], Fig. 1) was replaced with a stainless steel version. A glass-fiber epoxy (G10) plate was inserted inside the hollow 'island' ([4], Fig. 1). The coils were instrumented and vacuum impregnated with CTD-101 epoxy, repacked inside the reaction package, and cooled down to $4.2 \mathrm{~K}$ for $I_{\mathrm{c}}$ measurement. A picture of an impregnated coil is given in Fig. 1 and a schematic of the voltage tap configuration is given in Fig. 2. The coils were protected by a layer 1 to layer 2 imbalance quench detection system with a voltage resolution below $0.5 \mathrm{mV}$. The quench detection level for imbalance was set at $2.5 \mathrm{mV}$. No additional coil protection systems were applied. The current was ramped at $10 \mathrm{As}^{-1}$, increased with $50 \mathrm{~A}$ steps, and kept constant during the voltage measurements.

\section{B. Results and discussion}

The $I_{\mathrm{c}}$ values of the witness cable sections that were reacted with the coils, determined at $64 \mathrm{~K}$ and an electric field criterion

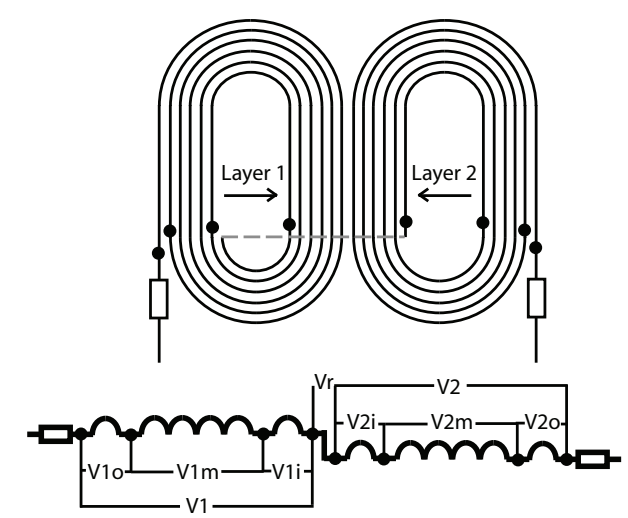

Fig. 2. Schematic representation of the voltage taps in coil HTS-SC07.

TABLE II

$I_{\mathrm{C}}$ VALUES FOR THE WITNESS CABLES OF HTS-SC-SERIES COILS AT $E_{\mathrm{c}}=10^{-4} \mathrm{VM}^{-1}$, AND $T=64 \mathrm{~K}$.

\begin{tabular}{lccccc}
\hline \hline Coil & SC03 & SC05 & SC07 & SC09 & SC11 \\
\hline Witness $I_{\mathrm{C}}[\mathrm{A}]$ & 387 & 264 & 239 & 242 & 246 \\
\hline \hline
\end{tabular}

$\left(E_{c}\right)$ of $10^{-4} \mathrm{Vm}^{-1}$, are summarized in Table II. The $30 \%$ reduction in witness cable $I_{\mathrm{c}}$ from coil HTS-SC03 to HTSSC05 is mainly due to the change from untwisted to twisted strand (Table I), which is known to give a $-20 \%$ reduction in the strand $I_{\mathrm{c}}$ [4]. The additional reduction could be due to a different effect of cabling on twisted and untwisted strand material, and/or to slight differences in the coil reaction heat treatments. The witness cables for coils HTS-SC07, HTS-SC09, and HTS-SC11, which were reacted together, are comparable. The ratio between a single strand $I_{\mathrm{c}}$ at $4.2 \mathrm{~K}$ in self-field, and a cable $I_{\mathrm{c}}$ at $64 \mathrm{~K}$ in self-field, is roughly 1.17 based on passed experience. This leads to approximate zero field short sample predictions (ignoring the self-field of the witness cables) of $5.2 \mathrm{kA}$ for coil HTS-SC05 and $4.7 \mathrm{kA}$ for coil HTS-SC07. The transfer function for the maximum field on the conductor in a $2 \times 6$ turn HTS subscale coil is $0.42 \mathrm{mTA}^{-1}$ [4], and this magnetic field is accounted for in the coil performance analysis. The $I_{\mathrm{c}}$ results at $64 \mathrm{~K}$ of the individual turns of coil HTS-SC09 are given in Table III. The results show that the inner turns carry, at $160 \mathrm{~A}$, approximately $65 \%$ of the $I_{\mathrm{c}}$ of the witness cable sample. It is striking to observe that the outer turns have an $I_{\mathrm{C}}$ that is approximately $30 \%$ increased with respect to the witness sample. The reason for this difference is unclear, but may be related to Oxygen, leakage, temperature, and/or strain gradients during reaction and cooldown. Further research will be performed to determine the origin of the observed variations along the coil sections.

The $4.2 \mathrm{~K} I_{\mathrm{c}}$ measurement on coil HTS-SC05 showed

TABLE III

$I_{\mathrm{C}}$ VALUES FOR INDIVIDUALLY TESTED TURNS OF COIL HTS-SC09 AT $E_{\mathrm{c}}=10^{-4} \mathrm{VM}^{-1}$, AND $T=64 \mathrm{~K}$.

\begin{tabular}{ccccc}
\hline \hline \multirow{2}{*}{ HTS-SC09 } & \multicolumn{2}{c}{ Layer 1 } & \multicolumn{2}{c}{ Layer 2 } \\
& Inner turn & Outer turn & Inner turn & Outer turn \\
\hline$I_{\mathrm{C}}[\mathrm{A}]$ & 160 & 320 & 160 & 320 \\
\hline \hline
\end{tabular}




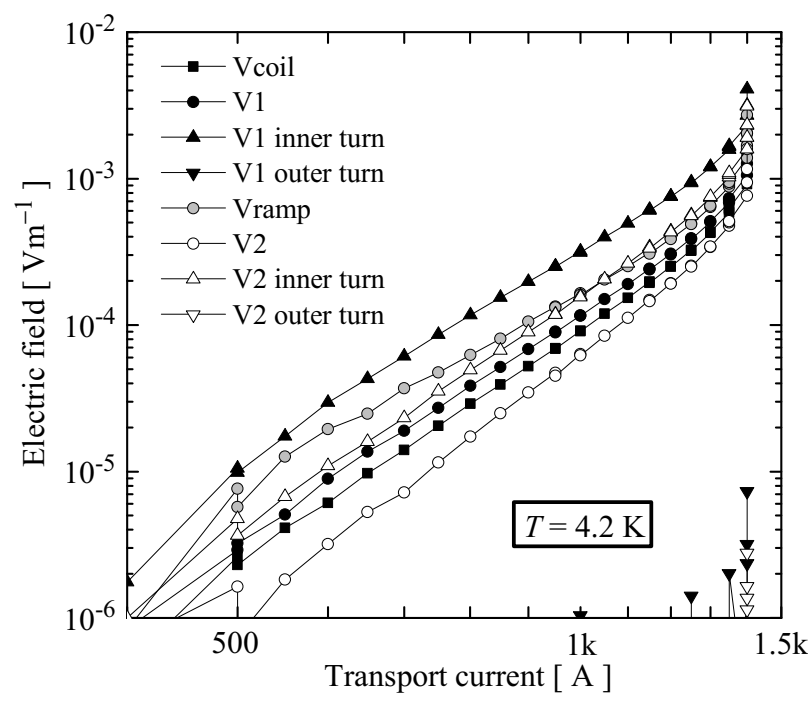

Fig. 3. Electric field as a function of current during a DC $I_{\mathrm{C}}$ test of coil HTS-SC07 at a temperature of $4.2 \mathrm{~K}$.

reproducible $E(I)$ transitions and thermal runaway around 1380 A. This reproducibility indicates that, at least at these relatively low currents and stored energies, voltage build-up and thermal runaway can be detected early and no quench induced damage occurs. The measured $I_{\mathrm{c}}$ at $E_{c}=10^{-4} \mathrm{Vm}^{-1}$ for coil HTS-SC05 is $964 \mathrm{~A}$, with an $n$-value of 6 , which indicates that this coil achieves around $20 \%$ of the estimated short sample, based on an estimated $10 \%$ reduction of $I_{\mathrm{c}}$ due to the $0.4 \mathrm{~T}$ on the conductor. The test indicated that, as with the $64 \mathrm{~K}$ tests on coil HTS-SC09, the inner turns limit the coil performance.

The voltage tap distribution for coil HTS-SC07, as schematically depicted in Fig. 2, allows for a more detailed analysis of the voltage buildup in the inner and outer turns, and across the transition from layer 1 to layer 2 (the ramp). The measured electric fields as functions of coil current are shown in Fig. 3. The calculated $I_{\mathrm{c}}$ and $n$-values at $E_{c}=10^{-4} \mathrm{Vm}^{-1}$ are summarized in Table IV. It is clear that, as was suspected from the test of coil HTS-SC05 and evident from the deconstructed coil HTS-SC09 tests, also HTS-SC07 is limited by the inner turns and the ramp. The outer turns on both layers only start developing detectable voltage close to the thermal runaway current, which was reproducibly located at $1400 \mathrm{~A}$. The $E(I)$ transitions are reproducible if sufficient time is allowed for cooling. The latter indicates that also for this coil no damage occurred as a result of thermal runaway. The total coil $I_{\mathrm{c}}$ corresponds to roughly $25 \%$ of the witness cable, if as before $10 \% I_{\mathrm{c}}$ reduction is estimated at $0.4 \mathrm{~T}$.

The performance of HTS-SC05 and HTS-SC07 is at approximately $20 \%$ and $25 \%$, respectively, significantly lower than worst (inner) sections in the deconstructed coil HTS-SC09, which were characterized at $64 \mathrm{~K}$ (Table III) and achieved about $65 \%$ of the witness cable $I_{\mathrm{c}}$. A significant difference between the HTS-SC09 turns measured at $64 \mathrm{~K}$ and the coils at $4.2 \mathrm{~K}$ is that HTS-SC09 was deconstructed at room temperature, and the turns were cooled down to $64 \mathrm{~K}$ in an unconfined state. The turns in the coils measured at $4.2 \mathrm{~K}$ were
TABLE IV

$I_{\mathrm{C}}$ AND $n$-VALUES AT $4.2 \mathrm{~K}$ FOR COIL HTS-SC07 AT AN ELECTRIC FIELD CRITERION OF $10^{-4} \mathrm{VM}^{-1}$.

\begin{tabular}{lcccc}
\hline \hline & \multicolumn{2}{c}{ Run 1 } & \multicolumn{2}{c}{ Run 2 } \\
Tap & $I_{\mathrm{c}}[\mathrm{A}]$ & $n$ & $I_{\mathrm{c}}[\mathrm{A}]$ & $n$ \\
\hline Vcoil & 1017 & 5 & 1015 & 5 \\
V1 & 970 & 5 & 969 & 5 \\
V1 inner turn & 785 & 5 & 782 & 5 \\
V1 outer turn & - & - & - & - \\
Vramp & 894 & 4 & 896 & 5 \\
V2 & 1080 & 6 & 1078 & 6 \\
V2 inner turn & 920 & 5 & 924 & 5 \\
V2 outer turn & - & - & - & - \\
\hline \hline
\end{tabular}

cooled down inside the reaction package. The INCONEL ${ }^{\circledR}$ Alloy 600 restricts the contraction of the windings to better match the $\mathrm{Bi}-2212$ as opposed to the thermal contraction of the cable. The philosophy behind this is to limit the strain on the superconducting volume by enforcing a known and selectable contraction, similar to $\mathrm{Bi}-2212$, on the entire package in an attempt to prevent irreversible $I_{\mathrm{c}}$ reductions due to strain [2], [4]. The present findings, however, could suggest that this method, though well established for short samples, may not work as expected in accelerator-type coils. Further work is needed to verify whether this is indeed the case.

\section{INSERT OPTIONS FOR HD2}

The $J_{\mathrm{c}}(H)$ behavior for both $\mathrm{Bi}-2212$ and YBCO conductors becomes rather flat and surpass that of $\mathrm{Nb}_{3} \mathrm{Sn}$ for fields above 18-22 T [5], [6]. This motivates the application of these two conductors as insert elements in existing high magnetic field [4]. Here preliminary designs of inserts based on $\mathrm{Bi}-$ 2212 and YBCO for the recently tested LBNL magnet HD2 are presented. $\mathrm{HD} 2$ is a $\mathrm{Nb}_{3} \mathrm{Sn}$ dipole magnet with a $36 \mathrm{~mm}$ bore developed at LBNL [7]. The bore field reached $13.8 \mathrm{~T}$ at $4.3 \mathrm{~K}$ in recent tests [8]. The dipole field generated by HD2 is assumed to be $13 \mathrm{~T}$ at $4.2 \mathrm{~K}$.

\section{A. $\mathrm{Bi}-2212$ vs. $\mathrm{Nb}_{3} \mathrm{Sn}$ round wires}

Fig. 4 shows the cross section of a quadrant of the insert and the HD2 coils structure. Region I is the bore ( $\varnothing 20 \mathrm{~mm})$. Region III is the structural support tube with an OD of $38 \mathrm{~mm}$ and ID of $30 \mathrm{~mm}$. Region II, composed of the insert coilpack, has a thickness of $5 \mathrm{~mm}$.

An insert based on tilted solenoids is suitable for round wires, e.g., Bi-2212 [9]. For a circular-aperture coil, the dipole field generated by a single layer of the wire is given by [10]

$$
B_{y, \mathrm{SL}}=\frac{\mu_{0} I}{2 d} \cos \alpha,
$$

where $I$ is the current in the wire, $d$ is the width or diameter of the conductor and $\alpha$ the tilted angle. When $N$ layers of conductor are superposed, the total field produced is $B_{y}=$ $N \cdot B_{y, \mathrm{SL}}$. Note that the field contributed is independent of coil radius.

Given $\alpha=20^{\circ}$, one can use $J_{\mathrm{c}}(H)$ for $\mathrm{Bi}-2212$ [5] and $\mathrm{Nb}_{3} \mathrm{Sn}$ round wires [11] to find the $B_{y}$ generated by the insert. 


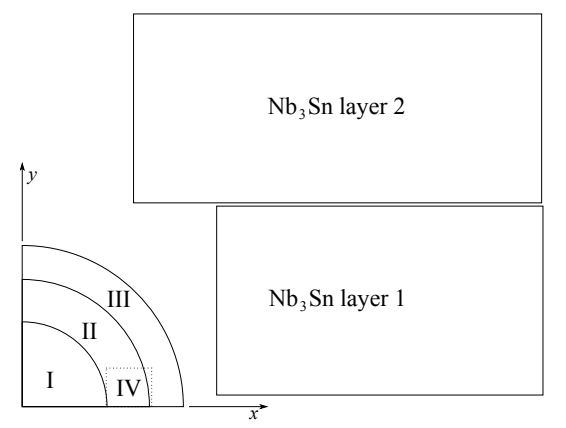

Fig. 4. Schematics of the cross section of a quadrant of the insert and HD2 coils structure.

TABLE V

COMPARISON BETWEEN BI-2212 AND NB 3 SN TILTED SOLENOIDS.

\begin{tabular}{lccccc}
\hline \hline Conductor & $d(\mathrm{~mm})$ & $N$ & $B_{y}(\mathrm{~T})$ & $I_{\mathrm{c}}(\mathrm{A})$ & $F_{x}$ (quadrant, MN/m) \\
\hline $\mathrm{Bi}-2212$ & 1. & 4 & 0.48 & 242 & 0.16 \\
$\mathrm{Nb}_{3} \mathrm{Sn}$ & 1.019 & 4 & 1.21 & 623 & 0.43 \\
\hline \hline
\end{tabular}

Table $\mathrm{V}$ lists the design results for the tilted solenoids based on $\mathrm{Bi}-2212$ and $\mathrm{Nb}_{3} \mathrm{Sn}$ conductors. The conductor diameter in Table $\mathrm{V}$ includes a $100 \mu \mathrm{m}$ thick insulation.

The $\mathrm{Bi}-2212$ and $\mathrm{Nb}_{3} \mathrm{Sn}$ inserts have similar transfer functions $(\sim 1.9 \mathrm{~T} / \mathrm{kA}$ for 4 layers) according to (1) because $d_{\mathrm{Nb}_{3} \mathrm{Sn}} \cong d_{\mathrm{Bi}-2212}$. However, because the $I_{\mathrm{c}}$ of the $\mathrm{Bi}-2212$ wire at $13.5 \mathrm{~T}$ is $242 \mathrm{~A}$, which is $39 \%$ of that of the $\mathrm{Nb}_{3} \mathrm{Sn}$ wire at $14.2 \mathrm{~T}$, the $\mathrm{Bi}-2212$ insert generates only $40 \%$ of the field given by the $\mathrm{Nb}_{3} \mathrm{Sn}$ insert. As noted earlier, HTS materials will surpass $\mathrm{Nb}_{3} \mathrm{Sn}$ only for fields $B \gtrsim 17 \mathrm{~T}$. The quadrant lateral force $\left(F_{x}\right)$ per unit length shown in Table $\mathrm{V}$ is estimated by using the total dipole field and the $\cos \theta$ distribution of the current density in the $z$ direction [9].

The effect on HD2 due to the insert field was investigated using Opera2D. Of particular interest is the field change in the pole turns of both coil layers where most of the quenches occurred during the HD2 test [8]. When the HD2 current is fixed and the insert current increases, the peak field seen by the pole turn in HD2 layer 1 will decrease and that seen by the pole turn in layer 2 will increase. However, the changes are both less than $4 \% / \mathrm{kA}$, which are believed to have little impact on the performance of HD2.

\section{B. YBCO coated conductors}

One of the advantages of YBCO conductors is that no heat treatment is necessary as opposed to either $\mathrm{Bi}-2212$ or $\mathrm{Nb}_{3} \mathrm{Sn}$ wires. However, the tape form makes a race-track coil more suitable for YBCO tapes than a tilted solenoid structure. Region IV in Fig. 4 denotes a quadrant of such a racetrack. The geometry of the block is $5.4 \times 4.6 \mathrm{~mm}^{2}$, corresponding to $27 \times 1$ turns of the conductor using $25 \mu \mathrm{m}$ thick insulation with $50 \%$ overlap. Assuming a self-field $I_{\mathrm{c}}$ of $80 \mathrm{~A}$ at $77 \mathrm{~K}$ and based on the normalized $I_{\mathrm{c}}(B)$ for a sample YBCO conductor [12], preliminary design results are listed in Table VI.

The YBCO racetrack coil has a transfer function of $\sim 1.8$ $\mathrm{T} / \mathrm{kA}$, which is slightly lower than that of the tilted solenoids. The effect on the pole turns of HD2 due to the racetrack coil was found to be similar to those of the tilted solenoid inserts. The changes are both less than $3 \% / \mathrm{kA}$.
TABLE VI

PERFORMANCE OF A YBCO RACETRACK INSERT (QUADRANT).

\begin{tabular}{ccccc}
\hline \hline Turns & $B_{y}(\mathrm{~T})$ & $\max B \| c(\mathrm{~T})$ & $I_{\mathrm{C}}(\mathrm{A})$ & $F_{x}(\mathrm{MN} / \mathrm{m})$ \\
\hline $27 \times 1$ & 0.80 & 1.25 & 440 & 0.37 \\
\hline \hline
\end{tabular}

\section{CONClusion}

The development of $\mathrm{Bi}-2212$ coils for accelerator magnet application is proceeding at LBNL in collaboration with wire manufacturer SWCC. A series of small racetrack prototypes have demonstrated the ability to successfully perform the requisite heat treatment, and has resulted in the development of appropriate tooling and instrumentation techniques to prepare coils for testing. First tests at LBNL have shown significant loss of $I_{c}$ with respect to witness samples. Work is ongoing to better understand and optimize the fabrication process, and improvements are being pursued by the wire manufacturer to reduce leakage; together these efforts are expected to mitigate the $I_{c}$ loss.

Case studies have been presented to use $\mathrm{Bi}-2212$ for tiltedsolenoid insert coils, and a comparison made with possible YBCO-tape racetrack insert coils, compatible with application in the LBNL HD2 dipole magnet. Such coils will aid in elucidating issues with the application of HTS technology to high-field accelerator applications. Bi-2212 inserts become more effective than $\mathrm{Nb}_{3} \mathrm{Sn}$ above about $17 \mathrm{~T}$. YBCO inserts are, for now, hindered by magnetic field components parallel to the $c$-direction.

\section{ACKNOWLEDGMENT}

The authors would like to thank P. Bish, H. C. Higley, D. Horler, N. L. Liggins, G. Ritchie, and J. Swanson for their technical expertise, and J. N. Giddings, C. D. English, and J. Ellias for their help with heat treatment and compatibility studies, and SEM and EDX analysis.

\section{REFERENCES}

[1] A. F. Lietzke et al., "Test results for HD1, a 16 Tesla $\mathrm{Nb}_{3} \mathrm{Sn}$ dipole magnet," IEEE Trans. Appl. Supercond., vol. 14, no. 2, p. 345, 2004.

[2] A. Godeke et al., "Limits of NbTi and $\mathrm{Nb}_{3} \mathrm{Sn}$, and development of W\&R Bi-2212 high field accelerator magnets," IEEE Trans. Appl. Supercond., vol. 17, no. 2, p. 1149, 2007.

[3] D. R. Dietderich, T. Hasegawa, Y. Aoki, and R. M. Scanlan, "Critical current variation of Rutherford cable of Bi-2212 in high magnetic fields with transverse stress," Physica C, vol. 341-348, no. 4, p. 2599, 2000.

[4] A. Godeke et al., "Development of wind-and-react Bi-2212 accelerator magnet technology," IEEE Trans. Appl. Supercond., vol. 18, no. 2, p. 516, 2008.

[5] K. Marken et al., "Progress in Bi-2212 wire and coils for superconducting magnets," Presentation HH4.6 at the MRS Spring Meeting, San Francisco, CA, USA, April 19, 2006.

[6] J. Schwartz et al., "High field superconducting solenoids via high temperature superconductors," IEEE Trans. Appl. Supercond., vol. 18, no. 2, p. 70, 2008.

[7] P. Ferracin et al., "Development of the $15 \mathrm{~T} \mathrm{Nb}_{3} \mathrm{Sn}$ dipole HD2," IEEE Trans. Appl. Supercond., vol. 18, no. 2, p. 277, 2008.

[8] P. Ferracin et al., "Assembly and test of HD2, a $36 \mathrm{~mm}$ bore high field $\mathrm{Nb}_{3} \mathrm{Sn}$ dipole magnet," 2008, 5LX08, submitted for publication in this conference.

[9] S. Caspi et al., "Design, fabrication, and test of a superconducting dipole magnet based on tilted solenoids," IEEE Trans. Appl. Supercond., vol. 17, no. 2, p. 2266, 2007.

[10] C. L. Goodzeit, M. J. Ball, and R. B. Meinke, "The double-helix dipole - a novel approach to accelerator magnet design," IEEE Trans. Appl. Supercond., vol. 13, no. 2, p. 1365, 2003. 
[11] A. Godeke, B. ten Haken, H. H. J. ten Kate, and D. C. Larbalestier, "A general scaling relation for the critical current density in $\mathrm{Nb}_{3} \mathrm{Sn}$ wires," Supercond. Sci. and Techn., vol. 19, p. R100, 2006.

[12] SuperPower Inc., "Field dependence of $I_{\mathrm{C}}$ of standard production wire," 2008. 